\title{
Whether Urbanization Has Intensified the Spread of Infectious Diseases - Renewed Question by the COVID-19 Pandemic
}

OPEN ACCESS

Edited by:

Mihajlo (Michael) Jakovljevic,

Hosei University, Japan

Reviewed by:

Abbas Sharifi,

Urmia University of Technology, Iran

Aurel Pera,

University of Craiova, Romania

Hsuling Chang,

Ling Tung University, Taiwan

${ }^{*}$ Correspondence:

Juanjuan Yu

562215326@qq.com

Specialty section

This article was submitted to

Health Economics,

a section of the journal

Frontiers in Public Health

Received: 24 April 2021

Accepted: 05 October 2021

Published: 24 November 2021

Citation:

Yu D, Li X, Yu J, Shi X, Liu P and

Tian P (2021) Whether Urbanization

Has Intensified the Spread of

Infectious Diseases-Renewed

Question by the COVID-19 Pandemic.

Front. Public Health 9:699710.

doi: 10.3389/fpubh.2021.699710

\author{
Dongsheng $Y u^{1}$, Xiaoping $L^{1}{ }^{1}$, Juanjuan $Y u^{1 *}$, Xunpeng Shi ${ }^{2}$, Pei Liu ${ }^{3}$ and Pu Tian ${ }^{1}$ \\ ${ }^{1}$ School of Economics, Zhongnan University of Economics and Law, Wuhan, China, ${ }^{2}$ Australia-China Relations Institute, \\ University of Technology Sydney, Sydney, NSW, Australia, ${ }^{3}$ School of Economics, Zhengzhou University of Aeronautics, \\ Zhengzhou, China
}

The outbreak of the COVID-19 epidemic has triggered adiscussion of the relationship between urbanization and the spread of infectious diseases. Namely, whether urbanization will exacerbate the spread of infectious diseases. Based on 31 provincial data from 2002 to 2018 in China, the impact of urbanization on the spread of infectious diseases from the dimensions of "population" and "land" is analyzed in this paper by using the GMM (generalized method of moments) model. The empirical study shows that the population increase brought by urbanization does not aggravate the spread of infectious diseases. On the contrary, urban education, employment and entrepreneurship, housing, medical and health care, and other basic public services brought by population urbanization can help reduce the risk of the spread of infectious diseases. The increasing density of buildings caused by land urbanization increases the risk of the spread of infectious diseases. Moreover, the impact of urbanization on the spread of infectious diseases has regional heterogeneity. Therefore, the prevention and control of disease play a crucial role.

Keywords: population urbanization, land urbanization, infectious diseases, public health, GMM model

\section{INTRODUCTION}

Public health is not only related to the national economy and the livelihood of the people but also concerns national security and social stability (1), especially during the COVID-19 pandemic. Therefore, the research on urban public health is of great importance for both country and people. The outbreak of the COVID-19 epidemic has triggered the discussion of the relationship between urbanization and the spread of infectious diseases. One hypothesis attributes the intensified transmission of COVID-19 to the "urban diseases" caused by the rapid urban expansion, such as increased population ratio, dense building, environmental pollution, and deteriorated sanitation by many people, which finally threatens residents' public health. The main basis of this hypothesis is that there is a significant gap in the number of confirmed COVID-19 cases between urban and rural areas in various cities. Especially in Hubei Province, most of the confirmed COVID-19 cases appeared in central urban areas, such as the urban areas of Wuhan City as well as the downtown areas of Xiaogan and Huanggang, both of which are near Wuhan. On the contrary, the morbidity rate in rural areas in Hubei Province is relatively low. They also found that since the government locked down Wuhan, most of the new cases in Hubei also appeared in Wuhan's urban area. 
The hypothesis owed the spread of COVID-19 to a "large population and too many buildings in big cities" and even claimed that the government should be restricting the population flow into large cities, evacuating urban populations, and reducing the building area, so as to prevent the spread of infectious diseases. Therefore, is the spread of Category B infectious diseases ${ }^{1}$ like SARS and COVID-19 really caused by a large population and building density in large cities? will urbanization exacerbate the spread of infectious diseases? In the context of the prevention and control of COVID-19, the answers to these questions have important reference value for correctly understanding and grasping urban public health safety, prevention, and treatment of infectious diseases, so as to propel the sustainable development of urbanization.

To explore the answers, we matched provincial data with health data to construct panel data in China's 31 provinces from 2002 to 2018, with a view to investigating the relationship between urbanization and the spread of infectious diseases.

The marginal contributions of this paper can be summarized as below. Firstly, the paper differentiates between population urbanization and land urbanization. "Population urbanization" is measured by the proportion of urban population, which is fundamentally different from "population density." "Land urbanization" is measured by the proportion of built-up area, which can reflect the density of urban buildings to some extent. Secondly, the morbidity and mortality of Category A and $B$ are used to reflect the spread of infectious diseases. The morbidity and mortality of Category A and B infectious diseases are significantly different from the population mortality (2), life expectancy per capita (3), newborn mortality (4), and prevalence of underlying diseases $(5,6)$ in the previous literatures. The former belongs to infectious diseases, which have the characteristics of "human-to-human transmission." It is more easily to measure the spread of infectious diseases. The latter is mainly to measure life health, which is a composite indicator. But the mortality and the ultimate lifespan and prevalence of underlying diseases do not belong to infectious diseases, and the death and lifespan may be determined by the infectious diseases or by other reasons. Therefore, the former index is more accurate, scientific, and suitable for the subject. Moreover, this is more in line with the theme of this study.

The remainder of the analysis is organized as follows: the Literature Review section shows a review of related papers. The model construction and variable selection of urbanization and the spread of infectious diseases is shown in the section Model and Variables. The data is presented in the Data section. The empirical analysis is presented in the Empirical Results section. This paper's research is summarized in the Conclusions and Policy Advice section. The limitations of the study are presented in the section Limitation.

\footnotetext{
${ }^{1}$ Category B infectious diseases include COVID-19, SARS, AIDS, pertussis, diphtheria, neonatal tetanus, malaria, H7N9 avian influenza and other 27 infectious diseases.
}

\section{LITERATURE REVIEW}

The spread of infectious diseases is the key area of urban public health and the weak link in the development of urban public health in recent years. The outbreak of COVID-19 in 2019 sounded an alarm for urban public health and safety. Research on the spread of infectious diseases initially belongs to the field of medical research, because medicine is committed to the treatment of diseases, to ensure people's life and health. Some scholars discussed the spatial distribution of the avian influenza (H5N1) outbreak (7), the regional differences of AIDS (8), the epidemic trend of pertussis (9), the regional distribution of neonatal tetanus cases (5), the dengue outbreak $(10,11)$, the transmission of COVID-19 (12-20) and other class A and $\mathrm{B}$ infectious diseases. These literatures mostly study the causes, laws, epidemic trends, and medical measures of infectious diseases from the perspective of medicine. This paper mainly discusses the impact of urbanization on the spread of infectious diseases from the perspective of sociology.

Many scholars have studied the social factors behind the spread of infectious diseases. Among them, the level of medical facilities is the most direct factor affecting the spread of infectious diseases. Mody et al. (21) based on the data of nursing homes in Michigan, found that the level of medical facilities in nursing homes is inversely proportional to the risk of disease infection of the elderly: that is, the higher the level of medical facilities in nursing homes, the lower the risk of disease infection of the elderly. Toda et al. (22) investigated the fatal cases of infectious diseases among children in Japan's top three hospitals and found that strengthening the construction of medical facilities can significantly reduce the proportion of children who died of infection. However, the level of economic development affects the regional medical level and then has an impact on the spread of infectious diseases. Bai et al. (23) uses the panel data of 29 regions in China to explore the impact of EPU on medical expenditure and finds that EPU has a positive spatial spillover effect on medical expenditure. Su et al. (24) found that there was an inverted U-shaped correlation between economic growth and health, and the health promotion effect of economic growth decreased significantly when it exceeded the threshold.

In addition, aging is also an important factor affecting the spread of infectious diseases (25). Hence, 2019 novel coronavirus pneumonia is mostly found in the elderly, and the death cases are mostly elderly. This is mainly because as age increases, people over 45 years old will gradually show the characteristics preceding old age, such as slow metabolism, decreased resistance, decreased physiological function $(26,27)$, poor awareness of disease prevention, and become a susceptible and high-risk group for infectious diseases. Heravi et al. (28) collected cases of infectious diseases in 65 year old patients who were treated in a hospital in Turkey for the years 2010-2011. It was found that the elderly were susceptible to infectious diseases, and the incidence rate and mortality rate were generally higher. The incidence rate and mortaity rate of 45 notifiable infectious diseases in China were assessed by Yang et al. (29). It was found that the incidence and mortality of notifiable infectious diseases in the 
elderly population were significantly higher than that in young people in the period 2004-2013.

In recent years, many scholars found that air pollution has become an important factor affecting the spread of infectious diseases. Jang et al. (30) collected 660,000 infectious diseases data in Korea and studied the relationship between air pollution level and the incidence rate of notifiable infectious diseases in that country. It was found that the incidence rate of infectious diseases was highly correlated with air pollution. Mody et al. (21) found that respiratory diseases and the spread of infectious diseases are related to the level of air pollution. The higher the level of air pollution exposure, the higher the risk of respiratory diseases and the spread of infectious diseases. Maji et al. (31) and Zeng et al. (32) found a similar view when studying the impact of PM2.5 on the spread of infectious diseases. However, different from the previous literature, this paper focuses on the impact of urbanization on the spread of infectious diseases.

Urbanization, as an important factor discussed in this paper, has a controversial impact on the spread of infectious diseases. Some scholars believe that the promotion of urbanization has produced an agglomeration effect, which has brought "urban diseases" such as housing congestion, traffic congestion, environmental pollution and health deterioration $(33,34)$, and increased the risk to urban residents (26). The incidence rate and mortality rate of malaria in Africa were studied by Hay et al. (35), which quantified the malaria burden in Africa. The cities' accelerated urban lifestyle increased malaria incidence and mortality in Africa. Wu et al. (36) compared the differences of avian influenza outbreaks between developing and developed countries and found that the interaction of urbanization, income growth, and globalization exacerbated the spread of infectious diseases.

Other scholars believe that urbanization will increase residents' income (37), improve medical facilities and security systems (38), and improve medical standards and services (39), thereby reducing the incidence rate and mortality of infectious diseases (40). Neiderud (41) compared the development of economy, health, environment, infrastructure, and other social aspects between urban and rural areas, and found that the living conditions of the urban environment are generally better than that of the rural environment, and better housing, health, ventilation, and social services play a positive role in the prevention and control of infectious diseases.

In addition, the ability to monitor and control projects, and the effect of prevention and public knowledge projects or campaigns in cities is much better than that in rural areas, and they are more able to respond to sudden infectious diseases in a timely manner. Wood et al. (42) evaluated the spatial-temporal relationship of infectious disease data in 60 medium-sized countries and found that urbanization improved urban health and medical conditions, increased medical investment, and helped to reduce the burden of the spread of infectious diseases. Bauer et al. (43) found a similar view using population data and general practitioner practice data in England. These literatures mostly investigate the impact of urbanization on public health; there is a lack of research on the relationship between urbanization and the spread of infectious diseases, and few literatures study this problem from the perspective of heterogeneous urbanization. This paper studies these two aspects.

\section{MODEL AND VARIABLES}

Based on the health production function proposed by Grossman (44) and referring to the method of Shao et al. (34), this paper integrates relevant factors affecting public health into the model and takes urbanization as an important factor affecting the spread of infectious diseases. The provincial health panel data of China's 31 provinces between 2002 and 2018 are used to empirically test the impact of urbanization on the spread of Category A and $B$ infectious diseases. The empirical analysis model is expressed as follows:

$$
\operatorname{lndisease}_{i t}=\alpha_{0}+\alpha_{1} \operatorname{lnurbanisation}_{i t}+\alpha_{2} \ln X_{i t}+\mu_{i t}
$$

where i represents China's 31 provinces and cities and t represents the year. disease reflects the spread of infectious diseases, urbanization represents the level of urbanization, $X_{i t}$ represents the control variable group, and $\mu$ is a random disturbance item. The indicators of each variable in the model are set as follows:

(1) The explained variable. This paper uses the morbidity and mortality of Category A and B legally reported infectious diseases to measure the spread of infectious diseases (disease). This is different from the population mortality (2), average life expectancy, and newborn mortality (3) in the previous literatures. The former belongs to the infectious diseases, which have the characteristics of "human-tohuman transmission" and can better measure the spread of such infectious diseases. The lower the morbidity and mortality of Category A and B legally reported infectious diseases, the slower the spread of infectious diseases and the better the control.

There are three specific reasons for selecting indicators of Category A and B infectious diseases for this paper. Firstly, COVID-19 has been classified as a Category B infectious disease. This paper is aimed to provide decisionmaking and reference for the prevention and control of COVID-19 through studying the previous data of Category $A$ and $B$ infectious diseases. Secondly, the morbidity and mortality of Category A and B infectious diseases are significantly different from the population mortality, average life expectancy, newborn mortality, and the prevalence of underlying diseases in the previous literatures. Thirdly, the indicators of Category A and B infectious diseases as used in this paper can also better respond to the hypothesis at the beginning of the article, which is also the author's original intention.

(2) Core explaining variables. Most of the literatures have used the ratio of urban population to total population in various regions to measure urbanization $(2,3)$. The indicator is fundamentally different from "population density," as it reflects the increase of population proportion brought by the acceleration of the urban process, but population density 
refers to the number of people per unit area. This paper mainly discusses whether the population proportion increase brought by the urbanization process exacerbates the spread of infectious diseases. Therefore, the former index could yield a more accurate result. Although this measurement index conforms to the study that "urbanization leads to too many people" mentioned above, it does not involve the dimension that "urbanization leads to too dense buildings" above. Therefore, on the basis of the existing literatures, this paper measures urbanization not only by using the proportion of urban population to the total population from the dimension of the "population," but also based on the proportion of the built-up area of a city to the total land area of the city area from the "land" dimension. To a certain extent, land urbanization can reflect the urban building density.

(3) Control variables. This paper uses the logarithm of the urban population density of different provinces and cities to measure population density, and compares it with the indicator of population urbanization, the main core explaining variable. In this paper, the dependency ratio of the elderly population in provinces and cities is used to measure the level of population aging (age) (3). Immunity is an important factor to resist infectious diseases. The elderly are worse than the young in terms of physical quality and physiological function (27), so their ability to fight against viruses is also naturally worse. The middle-aged and the elderly are more easily attacked by COVID-19, and most of the deaths are among the elderly. Moreover, in recent years, the problem of "getting old before getting rich" in China has constantly impacted regional economic growth, public health investment, and residents' medical consumption (45), which has a far-reaching impact on the health levels of residents. Per capita GDP (rgdp), which reflects the level of economic development and affects the income of residents, affects residents' health expenditure and health level (24), which affects the spread of infectious diseases. In this paper, the proportion of health expenditure to the total financial expenditure of provinces and cities is used to represent the public health input (expend), reflecting the importance of public health in the region. The medical development level (medical) is measured by the logarithm of the number of health technicians per 1,000 populations in cities, reflecting the regional medical construction level. The improvement of this indicator is conducive to the prevention, diagnosis, and treatment of infectious diseases. In this paper, the logarithm of the number of days with air quality reaching and better than level 2 in provinces and cities is used to measure the air quality level (air). Air is directly related to the spread of a great variety of respiratory diseases. Some of the pathogens can spread in the air freely, with the usual diameter of 5 microns. They can float on the surface dust in the air, floating in the air for a long time, and move for a long distance (46). The SARS virus in 2003 and COVID-19 in 2019 have the same principle. Therefore, air quality directly determines the speed and extent of disease spread.
TABLE 1 | The descriptive statistics of variables.

\begin{tabular}{lccccc}
\hline Variables & Observations & Mean & Standard & Min & Max \\
\hline Morbidity & 527 & 5.495 & 0.357 & 4.513 & 6.604 \\
Mortality & 527 & 0.609 & 0.382 & 0.068 & 2.122 \\
Population urbanization & 527 & 0.499 & 0.154 & 0.005 & 0.896 \\
Land urbanization & 527 & 0.154 & 0.104 & 0.006 & 0.637 \\
Population density & 527 & 7.341 & 0.796 & 5.231 & 8.608 \\
Age & 527 & 0.125 & 0.027 & 0.067 & 0.219 \\
Rgdp & 527 & 10.211 & 0.777 & 8.089 & 11.851 \\
Expend & 527 & 0.061 & 0.019 & 0.027 & 0.106 \\
Medical & 527 & 1.542 & 0.359 & 0.693 & 2.738 \\
Air & 527 & 5.638 & 0.242 & 3.892 & 5.903 \\
\hline
\end{tabular}

\section{DATA}

This paper builds health panel data of China's 31 provinces between 2002 and 2018 by matching the provincial data and health data. All data studied in this paper are from China Statistical Yearbook, China Health Statistical Yearbook, Statistical Yearbook of Provinces and Cities, National Economic and Social Development Statistical Publication, National Research Network Database, and Guotai Junan database. The descriptive statistics of variables in the model are shown in Table 1.

To reflect the relationship between population urbanization, land urbanization, and the spread of infectious diseases more intuitively, this paper draws the figures for the fitting relationships between population urbanization and land urbanization and the morbidity and mortality of Category $\mathrm{A}$ and $\mathrm{B}$ infectious diseases, which is shown as Figures 1, 2, respectively. As can be seen from Figure 1, the level of population urbanization is significantly negatively correlated with the morbidity and mortality of Category A and B infectious diseases. Moreover, the degree of negative correlation between population urbanization and the morbidity of Category A and $\mathrm{B}$ infectious diseases is significantly higher than that of mortality, indicating that with the increase of population urbanization rate, the morbidity and mortality of Category $A$ and $B$ infectious diseases are decreasing. As can be seen from Figure 2, the level of land urbanization is significantly positively correlated with the morbidity and mortality of Category $\mathrm{A}$ and $\mathrm{B}$ infectious diseases, indicating that with the increase of land urbanization rate, the morbidity and mortality of Category A and B infectious diseases are on the rise. The correlations between population urbanization and land urbanization and the morbidity and mortality of A and B infectious diseases are completely opposite, and urbanization in different dimensions may vary in terms of the spread of infectious diseases. Therefore, for the purpose of testing the real causal relationship between population urbanization and land urbanization and morbidity and mortality of Category A and $B$ infectious diseases, this paper will construct the provincial 


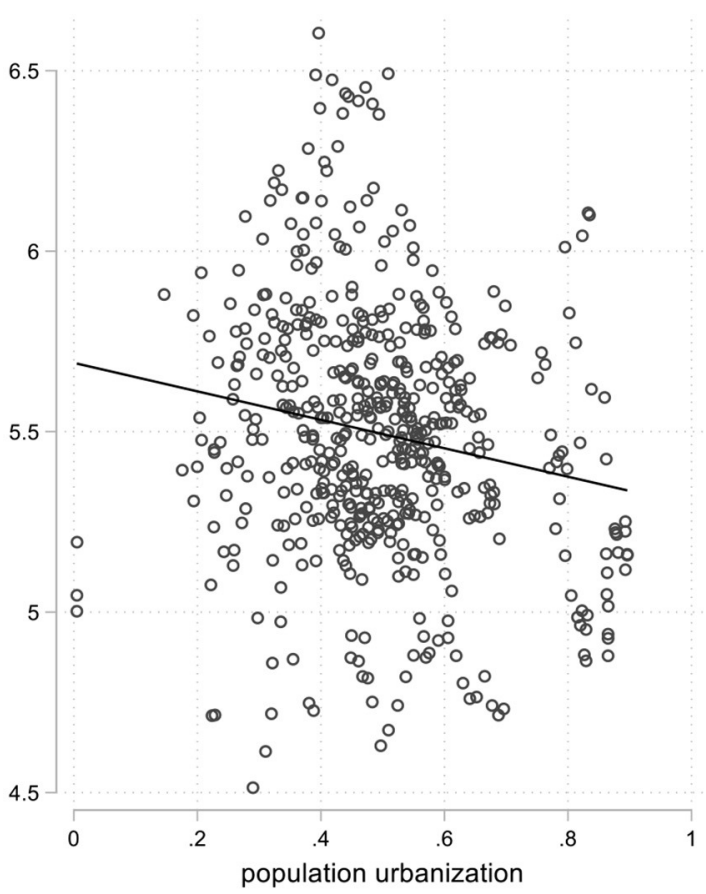

○ morbidity — Fitted values

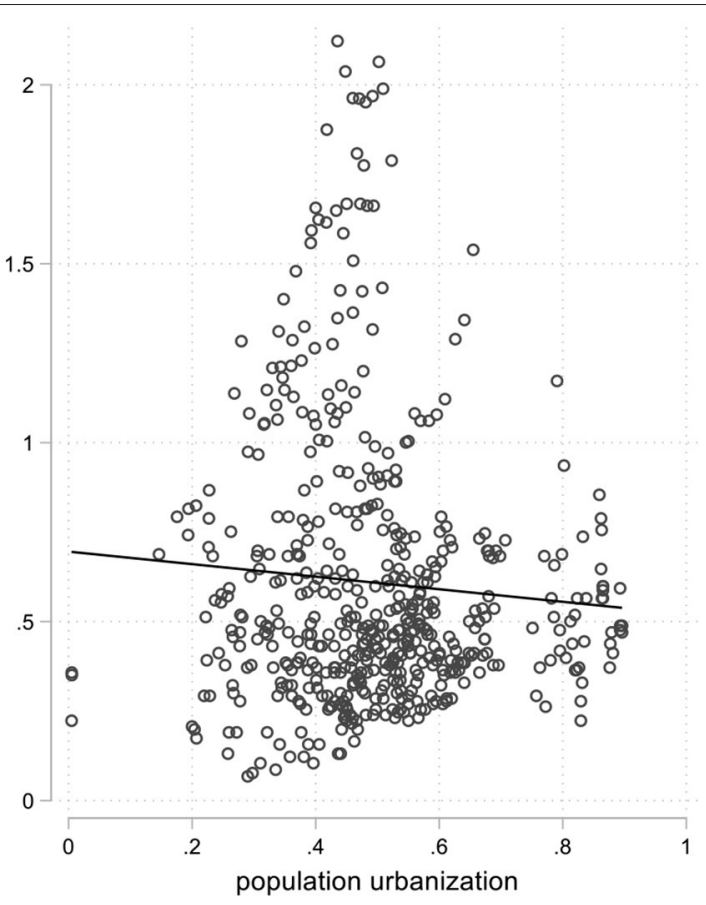

- mortality — Fitted values

FIGURE 1 | Fitting relationships between population urbanization and the morbidity and mortality.

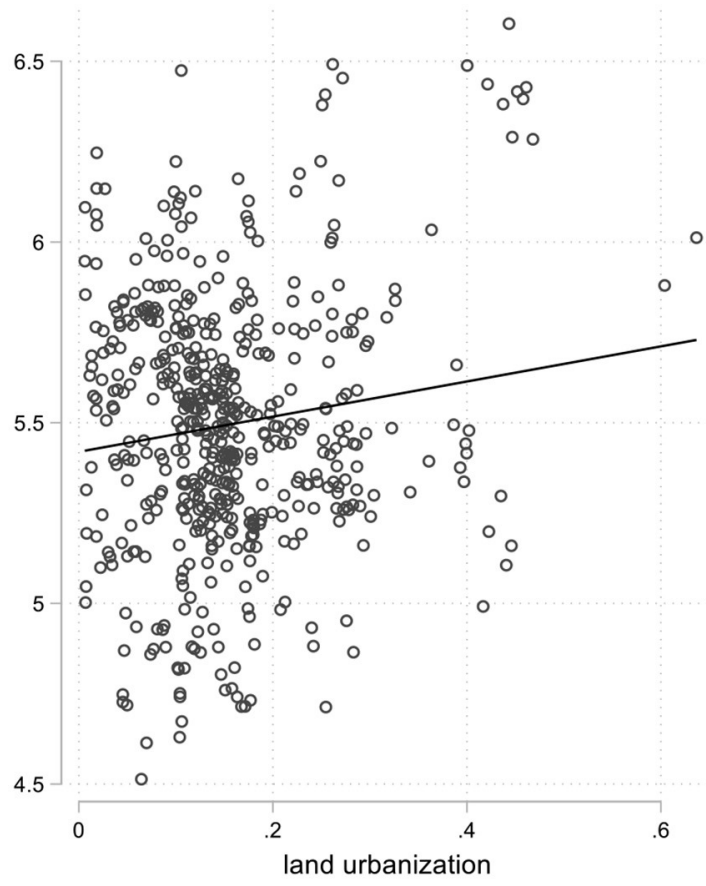

- morbidity — Fitted values

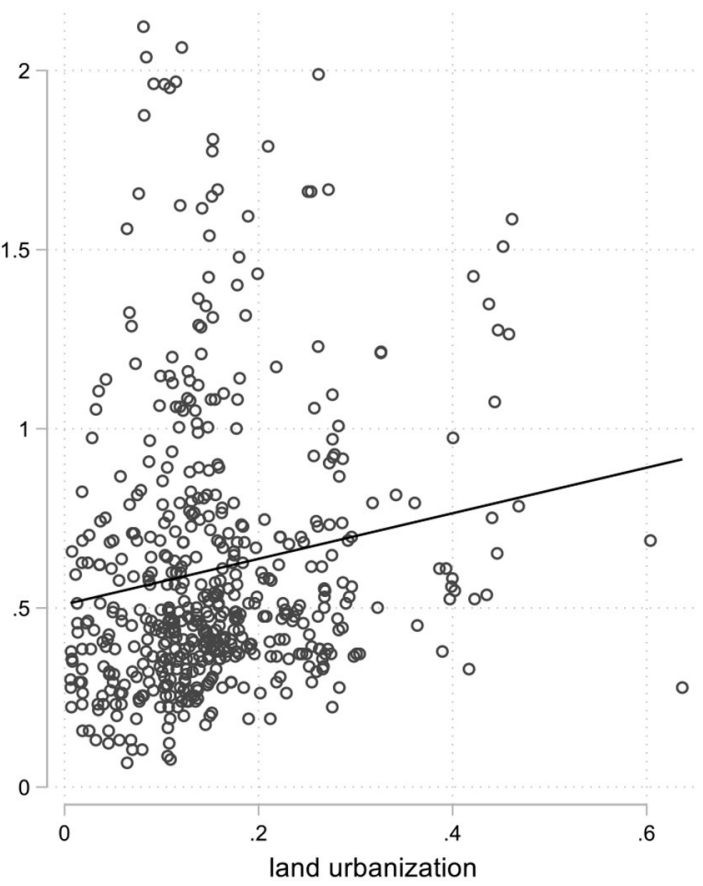

- mortality — Fitted values

FIGURE 2 | Fitting relationships between land urbanization and the morbidity and mortality. 
TABLE 2 | Baseline regression results of urbanization on the spread of infectious diseases.

\begin{tabular}{|c|c|c|c|c|c|c|c|c|}
\hline \multirow[t]{3}{*}{ Variables } & \multicolumn{4}{|c|}{ SYS-GMM } & \multicolumn{4}{|c|}{ DIFF-GMM } \\
\hline & (1) & (2) & (3) & (4) & (5) & (6) & (7) & (8) \\
\hline & Morbidity & Mortality & Morbidity & Mortality & Morbidity & Mortality & Morbidity & Mortality \\
\hline \multirow[t]{2}{*}{ Population urbanization } & $-0.359^{\star \star \star}$ & $-0.174^{\star \star \star}$ & & & $-0.364^{\star \star \star}$ & $-0.060^{\star \star}$ & & \\
\hline & $(-6.219)$ & $(-2.987)$ & & & $(-2.872)$ & $(-2.013)$ & & \\
\hline \multirow[t]{2}{*}{ Land urbanization } & & & $0.081^{\star \star}$ & $0.070^{\star \star}$ & & & $0.100^{\star \star}$ & $0.089^{\star *}$ \\
\hline & & & $(2.447)$ & $(2.530)$ & & & $(2.187)$ & $(2.049)$ \\
\hline \multirow[t]{2}{*}{ Population density } & 5.617 & 2.223 & 6.839 & 2.603 & 2.608 & 7.713 & 3.413 & 7.823 \\
\hline & $(1.548)$ & (1.603) & $(1.255)$ & $(1.077)$ & $(1.038)$ & $(1.213)$ & $(1.461)$ & $(1.131)$ \\
\hline \multirow[t]{2}{*}{ Age } & $1.119^{\star \star \star}$ & $1.539^{\star \star \star}$ & $0.958^{\star \star \star}$ & $1.479^{\star \star \star}$ & $1.330^{\star \star \star}$ & 0.242 & $1.341^{\star \star \star}$ & 0.017 \\
\hline & (3.095) & (6.776) & (3.416) & (6.268) & $(4.208)$ & $(0.965)$ & $(4.121)$ & $(0.062)$ \\
\hline \multirow[t]{2}{*}{ rgdp } & -0.020 & 0.020 & -0.064 & 0.007 & 0.021 & $0.199^{\star \star \star}$ & -0.009 & $0.213^{\star \star \star}$ \\
\hline & $(-0.741)$ & $(1.362)$ & $(-0.536)$ & $(0.451)$ & (0.583) & (3.531) & $(-0.344)$ & (3.839) \\
\hline \multirow[t]{2}{*}{ Expend } & -0.504 & $-2.063^{\star \star \star}$ & 0.179 & $-2.110^{\star \star \star}$ & $-1.898^{\star \star \star}$ & $-1.282^{\star \star \star}$ & $-1.646^{\star \star \star}$ & $-1.367^{\star \star \star}$ \\
\hline & $(-1.072)$ & $(-6.220)$ & $(0.556)$ & $(-6.583)$ & $(-3.291)$ & $(-3.867)$ & $(-3.115)$ & $(-4.215)$ \\
\hline \multirow[t]{2}{*}{ Medical } & 0.043 & $-0.057^{\star \star \star}$ & 0.018 & $-0.075^{\star \star \star}$ & -0.034 & 0.050 & $-0.083^{\star \star}$ & 0.064 \\
\hline & (1.035) & $(-2.850)$ & (0.553) & $(-3.898)$ & $(-0.820)$ & $(1.284)$ & $(-2.170)$ & $(0.732)$ \\
\hline \multirow[t]{2}{*}{ Air } & $-0.026^{\star \star}$ & -0.005 & $-0.031^{\star \star}$ & -0.016 & 0.014 & 0.004 & 0.016 & 0.008 \\
\hline & $(-2.072)$ & $(-0.431)$ & $(-2.346)$ & $(-1.213)$ & $(0.875)$ & $(0.274)$ & $(0.960)$ & $(0.494)$ \\
\hline \multirow[t]{2}{*}{ L.disease } & $0.683^{\star \star \star}$ & $0.776^{\star \star \star}$ & $0.653^{\star \star \star}$ & $0.797^{\star \star \star}$ & $0.552^{\star \star \star}$ & $0.287^{\star \star \star}$ & $0.518^{\star \star \star}$ & $0.314^{\star \star \star}$ \\
\hline & $(27.481)$ & (59.622) & (21.355) & (48.795) & $(10.064)$ & (3.863) & (8.790) & $(4.141)$ \\
\hline AR_1 & 0.0069 & 0.0007 & 0.0065 & 0.0006 & 0.0092 & 0.0696 & 0.0081 & 0.0479 \\
\hline AR_2 & 0.6825 & 0.7024 & 0.5544 & 0.7616 & 0.8279 & 0.5552 & 0.7203 & 0.4926 \\
\hline Sargan text & 0.4797 & 0.4137 & 0.4581 & 0.4475 & 0.459 & 0.4177 & 0.4278 & 0.433 \\
\hline Observations & 527 & 527 & 527 & 527 & 527 & 527 & 527 & 527 \\
\hline
\end{tabular}

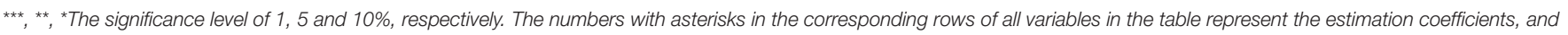
the values in the parentheses are the corresponding $T$ statistical values, and the P values of $A R \_1, A R \_2$, and Sargan test are provided respectively.

dynamic panel data GMM model in the next section for further empirical analysis.

\section{EMPIRICAL RESULTS}

The static panel estimation method is first adopted to estimate the panel data of China's 31 provinces between 2002 and 2018. The Hausman test for the endogeneity of explaining variables is also conducted. The $P$ value of the Hausman test is 0.0043 , rejecting the null hypothesis where all explaining variables are exogenous at the significance level of $1 \%$. Therefore, on the basis of static panel regression, this paper adds the first-order lag term of the explained variable to construct the provincial dynamic panel data GMM model for estimation. ${ }^{2}$ To overcome the endogeneity in the model, generalized moment GMM is selected to estimate the full sample data.

The specific estimated results are shown in Table 2, where, Equations (1)-(4) represent the GMM estimation results of the system, while Equations (5)-(8) represent the difference GMM

\footnotetext{
${ }^{2}$ Based on the moment condition, the GMM method constructs equations with parameters. It does not need to assume the distribution of variables, and does not need to know the distribution information of random interference terms, so it can effectively solve the endogenous problem.
}

estimation results. $P$ values provided by AR_2 of all the equations in Table 2 accept the null hypothesis at the significance level of $10 \%$, indicating that the residual sequence of the difference equation in the model has only first-order sequence correlation and no second-order sequence correlation. The model has passed the autocorrelation test. The $P$ values provided by Sargan test in Table 2 also accept the null hypothesis at the significance level of $10 \%$, indicating that all instrumental variables are strictly exogenous and valid. Therefore, the estimation results of difference GMM and system GMM are consistent and reliable. The significance and direction of the regression coefficients of the core explaining variables and control variables in Table $\mathbf{2}$ for the morbidity and mortality of Category A and B infectious diseases are roughly the same, which further indicates that the empirical results are reliable.

The results of both system GMM and differential GMM regression show that population urbanization has a significant negative impact on the morbidity and mortality of Category $\mathrm{A}$ and $\mathrm{B}$ infectious diseases, while land urbanization has a significant positive impact on the morbidity and mortality of both above. Taking the empirical results of system GMM as an example, the morbidity and mortality will be reduced by 0.359 and $0.174 \%$, respectively, with a $1 \%$ increase in population urbanization. The morbidity and mortality will be 
increased by 0.081 and $0.07 \%$, respectively, with a $1 \%$ increase in land urbanization. This indicates that the improvement of population urbanization is conducive to reducing the morbidity and mortality of Category A and B infectious diseases, while the improvement of land urbanization increases the morbidity and mortality of both above.

Population urbanization does not aggravate the spread of infectious diseases. This is because people rush to big cities to secure more job opportunities, better job welfare, higher incomes, more favorable education and health care services, etc. (47), which can be summarized as "the people's aspiration for a better life" as called by President Xi. The development of urbanization essentially lies in "humans," and "human needs." The increasing urban population has brought the development of urbanization, which contributes to the economic effect, income effect, scale effect, rich medical and health resources, improves the demand for health, and forms health consciousness, etc. (36-39). These channels all reduce the risk of the spread of infectious diseases.

Land urbanization increases the risk of the spread of infectious diseases. This is because land urbanization certainly reflects the degree of "urban building density," including the density of urban building land, industrial land, construction area, etc., which can directly affect the living environment, air quality, and health status of urban residents. With the enhancement of land urbanization, industrial building area, environmental pollution, and the decrease of ecological green space (48), the living environment and breathing air quality of citizens continuously deteriorate, which makes it possible to spread infectious diseases.

From the perspective of control variables, population density has no significant effect on the morbidity and mortality of Category A and B infectious diseases, indicating that the spread of infectious diseases has little relationship with population density. In the spread of infectious diseases, population density refers to the density in the sense of clustering. Even if you live in rural areas and the overall population density is not high, the disease will still spread if you live in groups. On the other hand, in areas with high population density in large cities, if efforts are made to avoid clustering and contact between people, there will be no transmission. So, disease prevention and control play a crucial role. Population aging has a significant positive impact on the morbidity and mortality of Category A and $\mathrm{B}$ infectious diseases, and the increase in the level of aging significantly increases the morbidity and mortality of Category A and $B$ infectious diseases, exacerbating the spread of infectious diseases. The reason may be that, compared with the young, the elderly have weaker constitution and a lower awareness of disease prevention, making them vulnerable and the high-risk groups for the spread of infectious diseases. This is consistent with the views of scholars Song and Yang (49). This is also the reason why the morbidity and mortality of COVID-19 are mainly among the middle-aged and the elderly. Therefore, attention shall be fully paid to the population aging. Per capita GDP has different influences on the morbidity and mortality of Category $A$ and $B$ infectious diseases but has no influence on the spread of infectious diseases. However, in the differential GMM model, per capita GDP has a positive influence on the mortality of Category
$A$ and $B$ infectious diseases. The reason is probably that the level of economic development increase is coupled with more serious environmental pollution, which is harmful to residents' health, induces diseases, increases the economic burden, and damages the labor ability. Thus, people will fall into poverty and be unable to bear the corresponding medical costs, eventually lost in the "poverty trap" of environmental health (50) and increasing the risk of death from infectious diseases. Level of investment in public health, medical development, and air quality on morbidity and mortality of Category A and B infectious diseases have significant negative effects, which suggests that the increase of the public health investment, medical development, and the improvement of air quality significantly reduce the morbidity and mortality of Category A and B infectious diseases, inhibiting the spread of infectious diseases.

The existing literature studies have shown that regions vary largely in terms of economic development, medical facilities, degree of aged individuals, and urbanization, leading to the obvious imbalance of health levels in different regions of China (1). To investigate the regional differences of the impact of Category A and B infectious diseases on urbanization, this paper divides all the samples into three regions, namely, the east, central and west parts, and tests the impact from the dimensions of population urbanization and land urbanization, respectively. Table 3 shows the estimated results of regional differences in the impact of population urbanization on Category A and B infectious diseases under the systematic GMM model.

As indicated by the results in Table 3, the $P$ values provided by AR_2 and Sargan tests both verify the null hypothesis at the significance level of $10 \%$, which further proves the reliability of the regression results. Population urbanization in eastern China has a significant negative impact on the morbidity and mortality of Category A and B infectious diseases, indicating that the improvement of population urbanization in eastern regions is conducive to reducing the risk of infectious disease spread, which is consistent with the results of the full sample estimation. The impact of population urbanization on the morbidity and mortality of Category A and B infectious diseases in the central and western regions is negative but insignificant. The positive effect of population urbanization on the prevention and control of infectious diseases in the central and western regions has not been shown. The main reason may be that, compared with the central and western regions, the eastern regions have relatively developed health levels, abundant education and medical resources, relatively intact public health systems, a high education level and income of residents, and more rigorous requirements for living environment and health. All of the above will indirectly improve the quality of life of the inhabitants, the prevention and control of infectious diseases, and health consciousness. The most important thing is that the residents' needs for higher material and cultural levels and a better and healthy life in the eastern region can be satisfied much faster than that of the population gathering in the eastern region. Therefore, the urbanization of the eastern region has a more negative impact on the spread of infectious diseases.

Table 4 shows the estimated results of regional differences in the impact of land urbanization on the spread of Category 
TABLE 3 | Regional differences in the impact of population urbanization.

\begin{tabular}{|c|c|c|c|c|c|c|}
\hline \multirow[t]{4}{*}{ Variables } & \multicolumn{6}{|c|}{ SYS-GMM } \\
\hline & \multicolumn{2}{|c|}{ Eastern region } & \multicolumn{2}{|c|}{ Central regions } & \multicolumn{2}{|c|}{ Western regions } \\
\hline & (1) & (2) & (3) & (4) & (5) & (6) \\
\hline & Morbidity & Mortality & Morbidity & Mortality & Morbidity & Morta \\
\hline \multirow{2}{*}{$\begin{array}{l}\text { Population } \\
\text { urbanization }\end{array}$} & $-0.6308^{\star}$ & $-0.2719^{\star \star}$ & -0.3562 & -0.4020 & -0.3042 & -0.6780 \\
\hline & $(-1.957)$ & $(-2.316)$ & $(-0.086)$ & $(-1.216)$ & $(-1.446)$ & $(-0.909)$ \\
\hline \multirow{2}{*}{$\begin{array}{l}\text { Population } \\
\text { density }\end{array}$} & 3.1638 & -7.4401 & -6.6646 & -8.8899 & 5.5022 & 2.4767 \\
\hline & (1.245) & $(-1.232)$ & $(-0.905)$ & $(-0.910)$ & $(0.778)$ & $(0.395)$ \\
\hline \multirow[t]{2}{*}{ Age } & 0.8588 & 1.0626 & $2.7547^{\star \star}$ & 1.0209 & 0.1665 & $0.6464^{\star}$ \\
\hline & $(1.101)$ & $(0.182)$ & (2.035) & $(1.178)$ & $(0.017)$ & (1.845) \\
\hline \multirow[t]{2}{*}{ rgdp } & 0.2820 & -0.1240 & $0.6602^{*}$ & -1.2548 & $-1.1821^{\star *}$ & -0.9506 \\
\hline & $(1.061)$ & $(-0.519)$ & (1.799) & $(-0.706)$ & $(-2.268)$ & $(-1.308$ \\
\hline \multirow[t]{2}{*}{ Expend } & $-1.0228^{\star}$ & -0.3583 & -1.1218 & 1.9069 & $-1.9507^{\star}$ & 0.7748 \\
\hline & $(-1.836)$ & $(-0.156)$ & $(-1.54$ & $(1.191)$ & $(-1.720)$ & $(0.671)$ \\
\hline \multirow[t]{2}{*}{ Medical } & $-0.2009^{\star \star}$ & $-0.4367^{\star \star}$ & $-0.3246^{*}$ & -0.4469 & -0.1684 & -0.4895 \\
\hline & $(-2.225)$ & (2.138) & $(-0.493)$ & $(-1.078)$ & $(-0.725)$ & $(-0.396$ \\
\hline \multirow[t]{2}{*}{ Air } & -0.0461 & -0.0440 & $-1.1638^{\star \star}$ & -0.3371 & -1.0795 & -0.179 \\
\hline & $(-1.294)$ & $(-0.640)$ & $(-2.1$ & $(-1.074)$ & $(-1.472)$ & $(-1.49$ \\
\hline \multirow[t]{2}{*}{ L.disease } & $0.6021^{\star \star \star}$ & $0.2870^{\star \star \star}$ & $-1.2830^{\star \star}$ & $-1.1777^{\star \star \star}$ & ${ }^{\star}-1.0159^{\star \star}$ & $3.4958^{\star \star}$ \\
\hline & (6.033) & (3.038) & $(-2.503)$ & $(-2.976)$ & $(-2.329)$ & (2.537) \\
\hline AR_1 & 0.0644 & 0.0221 & 0.0189 & 0.0168 & 0.0822 & 0.0243 \\
\hline AR_2 & 0.4952 & 0.6207 & 0.349 & 0.9265 & 0.7641 & 0.4104 \\
\hline Sargan text & 0.9998 & 1.0000 & 1.0000 & 1.0000 & 1.0000 & 1.0000 \\
\hline Observations & 204 & 204 & 153 & 153 & 170 & 170 \\
\hline
\end{tabular}

***, **, *The significance level of 1, 5 and 10\%, respectively. The numbers with asterisks in the corresponding rows of all variables in the table represent the estimation coefficients, and the values in the parentheses are the corresponding $T$ statistical values, and the $P$ values of $A R \_1, A R \_2$, and Sargan test are provided respectively.

A and B infectious diseases under the system GMM model. It can be seen from Table 4 that land urbanization in the eastern region has a significant negative impact on the morbidity of Category A and B infectious diseases, which reveals that the increase in land urbanization in the eastern region can help reduce the risk of infectious disease spread. It is not consistent with the estimated results. The impact of land urbanization on the morbidity and mortality of Category A and B infectious diseases in the central and western regions is significantly positive, indicating that the improvement of land urbanization in the western regions increases the risk of the spread of infectious diseases. The cause of the regional differences may be as follows:

In the process of urbanization, the eastern region adheres to the industrial transformation with the industrial structure level higher than that of the central and western regions. It strengthens the intensive utilization of land, protects the ecological environment of the cities, improves the urban living environment, and highlights green and healthy urbanization (48), so as to produce a positive "interactive" relationship between the land urbanization rate and infectious diseases prevention and control. Compared with the eastern region, the central and western regions have a lower level of economic
TABLE 4 | Regional differences in the impact of land urbanization.

\begin{tabular}{|c|c|c|c|c|c|c|}
\hline \multirow[t]{4}{*}{ Variables } & \multicolumn{6}{|c|}{ SYS-GMM } \\
\hline & \multicolumn{2}{|c|}{ Eastern region } & \multicolumn{2}{|c|}{ Central regions } & \multicolumn{2}{|c|}{ Western regions } \\
\hline & (1) & (2) & (3) & (4) & (5) & (6) \\
\hline & Morbidity & Mortality & Morbidity & Morbidity & Mortality & Morbidit \\
\hline \multirow{2}{*}{$\begin{array}{l}\text { Land } \\
\text { urbanization }\end{array}$} & $-0.9601^{\star \star \star}$ & -0.4067 & $0.6192^{\star \star}$ & $0.7437^{\star}$ & $0.0177^{\star \star}$ & $0.1575^{\star \star}$ \\
\hline & $(-2.880)$ & $(-0.597)$ & (2.326) & (1.829) & (2.017) & (2.349) \\
\hline \multirow{2}{*}{$\begin{array}{l}\text { Population } \\
\text { density }\end{array}$} & 3.3630 & -1.1657 & -3.3557 & -2.0959 & 4.2387 & 7.3419 \\
\hline & (1.166) & $(-0.928)$ & $(-0.480)$ & $(-0.483)$ & $(0.186)$ & (1.182) \\
\hline \multirow[t]{2}{*}{ Age } & 0.8765 & 0.3759 & $2.5570^{\star \star}$ & -6.1144 & 3.2429 & $1.3849^{\star \star}$ \\
\hline & (0.969) & $(0.053)$ & $(2.284)$ & $(-0.516)$ & $(0.100)$ & (2.347) \\
\hline \multirow[t]{2}{*}{ rgdp } & 0.1287 & -0.1024 & 0.6453 & 0.4276 & -0.7296 & -1.8042 \\
\hline & $(0.721)$ & $(-0.709)$ & (1.62 & $(0.641)$ & $(-0.164)$ & $(-1.470)$ \\
\hline \multirow[t]{2}{*}{ Expend } & $-0.1328^{\star \star}$ & -1.2658 & $-1.0627^{\star}$ & -1.5019 & -1.2157 & $1.8885^{\star \star}$ \\
\hline & $(-2.218)$ & $(-0.316)$ & $(-1.810)$ & $(-0.409)$ & $(-0.211)$ & (2.083) \\
\hline \multirow[t]{2}{*}{ Medical } & $-0.4360^{\star \star}$ & 0.0076 & $-5.6163^{\star}$ & 1.2861 & 2.4147 & 0.5866 \\
\hline & $(-2.190)$ & (0.099) & $(-1.930)$ & (0.515) & $(0.157)$ & (0.533) \\
\hline \multirow[t]{2}{*}{ Air } & $-0.0752^{* \star}$ & -0.0040 & 0.5108 & 0.0017 & -0.2058 & -0.1424 \\
\hline & $(-2.090)$ & $(-0.077)$ & (0.982) & $(0.017)$ & $(-0.101)$ & $(-0.405)$ \\
\hline \multirow[t]{2}{*}{ L.disease } & $0.5941^{\star \star \star}$ & $0.4867^{\star \star \star}$ & $-1.1119^{\star \star \star}$ & $1.4820^{\star \star \star}$ & $-0.1200^{\star \star \star}$ & $3.2418^{\star \star}$ \\
\hline & $(5.983)$ & (3.199) & $(-3.330)$ & (2.994) & $(-4.053)$ & (2.323) \\
\hline AR_1 & 0.0374 & 0.015 & 0.0163 & 0.0146 & 0.0662 & 0.0209 \\
\hline AR_2 & 0.4325 & 0.9854 & 0.2254 & 0.2385 & 0.7247 & 0.5320 \\
\hline Sargan text & 0.9998 & 1.0000 & 1.0000 & 1.0000 & 1.0000 & 1.0000 \\
\hline Observations & 204 & 204 & 153 & 153 & 170 & 170 \\
\hline
\end{tabular}

${ }^{* * *},{ }^{* *},{ }^{*}$ The significance level of 1, 5 and 10\%, respectively. The numbers with asterisks in the corresponding rows of all variables in the table represent the estimation coefficients, and the values in the parentheses are the corresponding $T$ statistical values, and the $P$ values of AR_1, AR_2, and Sargan test are provided respectively.

development and threshold for environmental regulation. They undertake the transfer of some polluting industries in the eastern region and face the threat of pollution transfer from the eastern region (51). The easily destroyed ecological environment, the increased environmental pollution, and the deteriorated urban living environment and air quality have augmented the risk of the spread of infectious diseases (52).

To test the conclusion robustness of this study, the differential GMM model is used to estimate the regional heterogeneity of population urbanization, land urbanization, and the spread of infectious diseases. The specific regression results are shown in Tables 5, 6. To be specific, Tables 5, 6 show the robustness test results of the impact of population urbanization and land urbanization on the spread of infectious diseases, respectively. According to the regression results in Tables 5, 6, the direction and significance of the regression coefficients of population urbanization and land urbanization on the morbidity and mortality of Category A and B infectious diseases are roughly the same as those in Tables 3, 4, except for coefficients which are different. It further proves that the research conclusions of this paper are robust and reliable. 
TABLE 5 | The robustness test of population urbanization.

\begin{tabular}{|c|c|c|c|c|c|c|}
\hline \multirow[t]{4}{*}{ Variables } & \multicolumn{6}{|c|}{ DIFF-GMM } \\
\hline & \multicolumn{2}{|c|}{ Eastern region } & \multicolumn{2}{|c|}{ Central regions } & \multicolumn{2}{|c|}{ Western regions } \\
\hline & (1) & (2) & (3) & (4) & (5) & (6) \\
\hline & Morbidity & Mortal & Morbidity & Morbidity & Mortality & Morbic \\
\hline \multirow{2}{*}{$\begin{array}{l}\text { Population } \\
\text { urbanization }\end{array}$} & $-1.0352^{\star}$ & $-2.1906^{\star}$ & -0.8034 & -1.4020 & $-1.1195^{\star}$ & -0.4863 \\
\hline & $(-1.853)$ & $(-1.755)$ & $(-1.062)$ & $(-1.259)$ & $(-1.686)$ & $(-0.107)$ \\
\hline \multirow{2}{*}{$\begin{array}{l}\text { Population } \\
\text { density }\end{array}$} & 1.9029 & -5.1416 & 1.6359 & -2.8899 & 2.4529 & 6.5785 \\
\hline & $(1.642)$ & $(-1.319)$ & (1.549) & $(-0.946)$ & (1.589) & $(1.387)$ \\
\hline \multirow[t]{2}{*}{ Age } & 1.1913 & $3.1623^{\star \star}$ & 0.2904 & 57.0209 & 2.2026 & -0.3496 \\
\hline & (1.315) & $(1.966)$ & (0.038) & $(1.216)$ & $(0.270)$ & $(-0.103)$ \\
\hline \multirow[t]{2}{*}{ rgdp } & $0.4467^{\star \star}$ & $0.7777^{\star}$ & $1.6158^{\star \star}$ & -1.2548 & -0.9862 & -0.4307 \\
\hline & (2.026) & (1.689) & $(2.097)$ & $(-0.725)$ & $(-1.072)$ & $(-1.175)$ \\
\hline \multirow[t]{2}{*}{ Expend } & -2.7409 & -0.3739 & 0.8189 & 1.9069 & -0.4761 & 1.2627 \\
\hline & $(-1.128)$ & $(-1.318)$ & (0.795) & $(1.246)$ & $(-1.621)$ & $(1.418)$ \\
\hline \multirow[t]{2}{*}{ Medical } & $-0.3118^{\star \star \star}$ & * 0.0167 & -1.8586 & -3.4469 & 8.0402 & 2.3041 \\
\hline & $(-3.072)$ & $(0.200)$ & $(-0.804)$ & $(-1.130)$ & (1.494) & $(1.243)$ \\
\hline \multirow[t]{2}{*}{ Air } & -0.0220 & $-0.0677^{\star}$ & -0.5670 & 0.3371 & -0.9307 & -0.1791 \\
\hline & $(-0.618)$ & $(-1.688)$ & $(-1.074)$ & $(1.121)$ & $(-1.349)$ & $(-1.087)$ \\
\hline \multirow[t]{2}{*}{ L.disease } & $0.5536^{\star \star \star}$ & $-1.2917^{\star \star}$ & $0.5408^{\star \star \star}$ & $-1.1777^{\star \star \star}$ & ${ }^{\star}-0.9155^{\star \star \star}$ & $-0.1776^{\star \star}$ \\
\hline & (5.062) & $(-2.067)$ & (2.912) & $(-3.037)$ & $(-3.321)$ & $(-4.259)$ \\
\hline AR_1 & 0.0519 & 0.0364 & 0.0217 & 0.0926 & 0.0866 & 0.0658 \\
\hline AR_2 & 0.528 & 0.518 & 0.1518 & 0.1422 & 0.2762 & 0.2693 \\
\hline Sargan text & 0.8934 & 0.9953 & 1.0000 & 1.0000 & 1.0000 & 1.0000 \\
\hline Observations & 204 & 204 & 153 & 153 & 170 & 170 \\
\hline
\end{tabular}

***, **, *The significance level of 1, 5 and 10\%, respectively. The numbers with asterisks in the corresponding rows of all variables in the table represent the estimation coefficients, and the values in the parentheses are the corresponding $T$ statistical values, and the $P$ values of $A R \_1, A R \_2$, and Sargan test are provided respectively.

\section{CONCLUSION AND POLICY ADVICE}

The COVID-19 pandemic renewed a question of whether the increase in population and the dense construction caused by urbanization increases the spread of infectious disease? To explore the relationship between urbanization and the spread of infectious diseases, this paper matches provincial data and health data to construct the panel data of China's 31 provinces between 2002 and 2018. Also, a GMM model is used to empirically evaluate the impact of urbanization on the morbidity and mortality of Category A and B infectious diseases from the dimensions of "population" and "land." Findings are listed as below:

Firstly, the full sample regression results show that population urbanization and land urbanization have opposite effects on the morbidity and mortality of Category A and B infectious diseases. Higher population urbanization reduces the morbidity and mortality of Category A and B infectious diseases and inhibits the spread of infectious diseases. On the contrary, a higher land urbanization rate increases the morbidity and mortality of Category A and B infectious diseases and intensifies the spread of Category A and B infectious diseases.
TABLE 6 | The robustness test of land urbanization.

\begin{tabular}{|c|c|c|c|c|c|c|}
\hline \multirow[t]{4}{*}{ Variables } & \multicolumn{6}{|c|}{ DIFF-GMM } \\
\hline & \multicolumn{2}{|c|}{ Eastern region } & \multicolumn{2}{|c|}{ Central regions } & \multicolumn{2}{|c|}{ Western regions } \\
\hline & (1) & (2) & (3) & (4) & (5) & (6) \\
\hline & Morbidity & Mortality & Morbidity & Morbidity & Mortality & Morbidity \\
\hline \multirow{2}{*}{$\begin{array}{l}\text { Land } \\
\text { urbanization }\end{array}$} & $-0.9252^{\star \star \star}$ & -1.6577 & $0.6192^{\star \star}$ & 0.7437 & $0.1210^{\star \star \star}$ & $0.0378^{* *}$ \\
\hline & $(-2.776)$ & $(-0.768)$ & $(2.402)$ & (1.339) & (2.934) & $(2.390)$ \\
\hline \multirow{2}{*}{$\begin{array}{l}\text { Population } \\
\text { density }\end{array}$} & 8.7626 & 2.0615 & -3.3557 & -2.0959 & 6.8670 & 3.3015 \\
\hline & $(0.950)$ & $(0.405)$ & $(-0.544)$ & $(-0.543)$ & $(1.071)$ & $(0.709)$ \\
\hline \multirow[t]{2}{*}{ Age } & 1.0876 & -1.0846 & $2.5570^{\star \star}$ & -6.1144 & 1.3447 & $7.4087^{\star}$ \\
\hline & (0.769) & $(-0.640)$ & $(2.474)$ & $(-0.590)$ & (1.599) & $(1.862)$ \\
\hline \multirow[t]{2}{*}{ Rgdp } & 0.14 & 0.3092 & $0.6453^{*}$ & 0.4276 & $-0.7101^{\star \star}$ & -0.9036 \\
\hline & $(1.047)$ & $(0.975)$ & $(1.825)$ & $(0.716)$ & $(-2.277)$ & $(-1.019)$ \\
\hline \multirow[t]{2}{*}{ Expend } & -0.2799 & -2.8727 & $-1.0627^{\star \star}$ & -1.5019 & -1.1651 & 1.3852 \\
\hline & $(-0.087)$ & $(-0.461)$ & $(-2.043)$ & $(-0.468)$ & $(-1.456)$ & $(1.635)$ \\
\hline \multirow[t]{2}{*}{ Medical } & $-0.2358^{\star *}$ & $0.1492^{*}$ & $-0.6163^{\star *}$ & 1.2861 & 0.1989 & 0.1083 \\
\hline & $(-2.178)$ & $(1.819)$ & $(-2.133)$ & $(0.579)$ & $(1.007)$ & $(0.156)$ \\
\hline \multirow[t]{2}{*}{ Air } & -0.1463 & 0.0500 & 0.5108 & 0.0017 & -0.1499 & -0.0555 \\
\hline & $(-0.969)$ & $(1.297)$ & $(1.103)$ & $(0.017)$ & $(-1.055)$ & $(-0.228)$ \\
\hline \multirow[t]{2}{*}{ L.disease } & $0.5321^{\star \star \star}$ & $-0.8979^{\star \star \star}$ & $-1.1119^{\star \star \star}$ & $1.4820^{\star \star \star}$ & $-0.3722^{\star \star \star}$ & $1.8112^{\star \star \star}$ \\
\hline & $(4.658)$ & $(-2.998)$ & $(-3.528)$ & (3.098) & $(-2.949)$ & (3.643) \\
\hline AR_1 & 0.0267 & 0.018 & 0.0407 & 0.0131 & 0.0162 & 0.0129 \\
\hline AR_2 & 0.1346 & 0.5454 & 0.204 & 0.1463 & 0.2434 & 0.4116 \\
\hline Sargan text & 0.7656 & 0.8976 & 1.0000 & 1.0000 & 0.9995 & 0.9683 \\
\hline Observations & 204 & 204 & 153 & 153 & 170 & 170 \\
\hline
\end{tabular}

${ }^{\star * *},{ }^{* \star},{ }^{*}$ The significance level of 1, 5 and $10 \%$, respectively. The numbers with asterisks in the corresponding rows of all variables in the table represent the estimation coefficients, and the values in the parentheses are the corresponding $T$ statistical values, and the $P$ values of $A R \_1, A R \_2$, and Sargan test are provided respectively.

Secondly, according to the results of regional heterogeneity regression, due to the developed medical level, rich educational and medical resources, public health system, and high quality of living environment and health requirements in eastern regions, the negative impact of population urbanization level on the spread of infectious diseases in eastern regions is more obvious than that in central and western regions.

Thirdly, population density has no obvious impact on the spread of infectious diseases so disease prevention and control play a crucial role. To a certain extent, the increase of the aging population and per capita GDP enhances the risk of the spread of infectious diseases. The enhancement of investment in public health, medical development, and air quality make the spread of infectious diseases less risky.

The policy inspirations of the conclusion in this paper mainly involve the following several aspects:

Firstly, China should continue to promote the "peopleoriented" new urbanization construction and expand the positive effects of population urbanization on the prevention and control of infectious diseases and public health. In the face of the increasing proportion of urban population brought by urbanization, the government should not limit the inflow of population but improve the level of urban technology and 
management by adjusting production and lifestyle, so that people's demands for a better and healthier life can be met faster than population growth. The reform of the household registration system is particularly important, so efforts should be made to actively promote the adjustment and improvement of the points-based household registration policy in megacities and supercities. A mechanism has been established to link the basic public services such as urban education, employment and entrepreneurship, and medical and health care to the permanent population, so as to avoid the influence of population mobility on the epidemic spread. In this way, China can actively cope with the challenges to the prevention and control of infectious diseases and public health brought by the increase of urban population.

Secondly, China should have the consciousness of "safety blank" for the urban development, that is to optimize the urban space layout without blind expansion and excessive land development, so as to make the production space more intensive and efficient. Protecting the urban ecological and living environment can make land urbanization bring a positive "interactive" relationship with the prevention and control of infectious diseases and public health, thus maximizing the sustainability of urban development.

Thirdly, China should build infrastructure services such as health care, education, and old-age care that are compatible with urbanization, and improve the public health management system and the "diversified" old-age security system. In this way, the negative effects of urbanization on the public health of residents can be reduced, and high-quality public resources can better serve local residents, so as to deal with public health emergencies such as the outbreak of infectious diseases more calmly.

Fourthly, when formulating the policies with regard to the prevention and control of infectious diseases and public health, the government should consider the impact of regional differences and the local realities. In particular, efforts should be made to strengthen the input of public resources such as medical treatment, health, and education in the central and western regions. China should strengthen environmental regulation thresholds, protect the ecological environment, promote equal access to public health services in all regions, improve the ability to prevent and control infectious diseases and the health of

\section{REFERENCES}

1. Zhao XY, Wang WJ, Wan WY. Regional differences in health level of Chinese residents: 2003-2013. Acta Geogr Sin. (2017) 4:685-98

2. Chang QQ, Zhong WZ. Does urbanization promote the improvement of public health level. Econ Surv. (2018) 6:127-34. doi: 10.15931/j.cnki.1006-1096.20180925.005

3. Cheng MM, Yang MZ. Impact of urbanization on health status of Chinese residents: an empirical analysis based on provincial panel data. China Popul Resourc Environ. (2015) 7:89-96.

4. Bakari A, Bell AJ, Oppong S. Asram is really killing us here: attribution for pregnancy losses and newborn mortality in the Ashanti region of Ghana. J Biosoc Sci. (2020) 53:497-507. doi: 10.1017/S00219320200 00322 residents, so as to achieve healthy and balanced development in all regions.

\section{LIMITATION}

This article has two limitations: firstly, this paper uses the previous data to discuss the relationship between urbanization and the spread of infectious diseases. It would be better if it could be combined with the latest COVID-19 data. However, the dimensions of urbanization and COVID-19 data are different, so it is impossible to conduct empirical analysis. Therefore, the research of this paper can provide a reference for related research in the future. Secondly, there are many factors affecting the spread of infectious diseases. Only some factors can be controlled in this paper, and there is no way to comprehensively consider the impact of other factors on the results in this paper, such as ecological fallacy, solar radiation, and so on. These are the focus of our next research.

\section{DATA AVAILABILITY STATEMENT}

The original contributions presented in the study are included in the article/supplementary material, further inquiries can be directed to the corresponding author.

\section{AUTHOR CONTRIBUTIONS}

DY: data curation, conceptualization, methodology, and writing-reviewing and editing. XL: data curation and writingoriginal draft preparation. JY: visualization and investigation. XS: writing-original draft preparation and investigation. PL: validation and writing-reviewing and editing. PT: writingreviewing and editing. All authors contributed to the article and approved the submitted version.

\section{FUNDING}

The authors gratefully acknowledge funding from Research Projects No. 18ZDA038 from the National Social Science Fund of China and No. 20BJL053 from the National Social Science Fund of China.
5. Amaliana L, Usa A, Wardhani NS. Modeling tetanus neonatorum case using the regression of negative binomial and zero-inflated negative binomial. JPhys Conf. (2017) 943:012051. doi: 10.1088/1742-6596/943/1/012051

6. Yong JC, Park JY, Lee HS, Suh J, Song JY, Byun MK, et al. Variable effects of underlying diseases on the prognosis of patients with COVID-19. PLoS One. (2021) 16:1-13. doi: 10.1371/journal.pone.0254258

7. Sengupta R, Rosenshein L, Gilbert M, Weiller C. Ecoregional dominance in spatial distribution of avian influenza (H5N1) outbreaks. Emerg Infect Dis. (2007) 13:1269-70. doi: 10.3201/eid1308.070329

8. Mogens KJ. Democracy, dictatorship, and disease: political regimes and HIV/AIDS. Eur J Polit Econ. (2012) 28:373-89. doi: 10.1016/j.ejpoleco.2012.02.001

9. Tan T, Dalby T, Forsyth K, Halperin S, Heininger U, Hozbor D, et al. Pertussis across the globe: recent epidemiologic trends from 2000 to 2013. Pediatr Infect Dis J. (2015) 34:222-32. doi: 10.1097/INF.0000000000000795 
10. Withanage GP, Gunawardana M, Viswakula SD, Samaraweera K. Multivariate spatio-temporal approach to identify vulnerable localities in dengue risk areas using Geographic Information System (GIS). Sci Rep. (2021) 11:1-11. doi: 10.1038/s41598-021-83204-1

11. Nguyen TT, Do DC, Le XL, Dinh TH. Risk factors of dengue fever in an urban area in Vietnam: a case-control study. BMC Public Health. (2021) 21:664. doi: 10.1186/s12889-021-10687-y

12. Ramírez-Aldana R, Gomez-Verjan JC, Bello-Chavolla OY. Spatial analysis of COVID-19 spread in Iran: insights into geographical and structural transmission determinants at a province level. PLoS Neglected Trop Dis. (2020) 14:e0008875. doi: 10.1371/journal.pntd.0008875

13. Gao CC Li SH, Liu M, Zhang FY, Achal V, Tu Y, et al. Impact of the COVID-19 pandemic on air pollution in Chinese megacities from the perspective of traffic volume and meteorological factors. Sci Total Environ. (2021) 773:145545. doi: 10.1016/j.scitotenv.2021.145545

14. Tan AX, Hinman JA, Magid H, Nelson LM. Association between income inequality and county-level COVID-19 cases and deaths in the US. JAMA Netw Open. (2021) 4:218799. doi: 10.1001/jamanetworkopen.2021.8799

15. Ahmadi M, Sharifi A, Khalili S. Presentation of a developed sub-epidemic model for estimation of the COVID-19 pandemic and assessment of travel-related risks in Iran. Environ Sci Pollut Res. (2021) 12:14521-9. doi: 10.1007/s11356-020-11644-9

16. Ahmadi M, Sharifi A, Dorosti S, Ghoushchi SJ, Negar G. Investigation of effective climatology parameters on COVID-19 outbreak in Iran. Sci Total Environ. (2020) 729:138705. doi: 10.1016/j.scitotenv.2020.138705

17. Rogers R. Internet of things-based smart healthcare systems, wireless connected devices, and body sensor networks in COVID-19 remote patient monitoring. Am J Med Res. (2021) 1:71-80. doi: 10.22381/ajmr8120217

18. Morgan V, Birtus M, Zauskova A. Medical internet of things-based healthcare systems, wearable biometric sensors, and personalized clinical care in remotely monitoring and caring for confirmed or suspected COVID-19 patients. Am J Med Res. (2021) 1:81-90. doi: 10.22381/ajmr8120218

19. Bailey L. Wearable internet of things healthcare systems, virtual care, and realtime clinical monitoring in assessing and treating patients with COVID-19 symptoms. Am J Med Res. (2021) 1:91-100. doi: 10.22381/ajmr8120219

20. Lyons N, Lăzăroiu G. Addressing the COVID-19 crisis by harnessing internet of things sensors and machine learning algorithms in datadriven smart sustainable cities. Geopolit Hist Int Relat. (2020) 2:65-71. doi: 10.22381/GHIR12220209

21. Mody L, Gibson KE, Horcher A, Prenovost K, Mcnamara SE, Foxman B, et al. Prevalence of and risk factors for multidrug-resistant acinetobacter baumannii colonization among high-risk nursing home residents. Infect Control Hosp Epidemiol. (2015) 36:1155-62. doi: 10.1017/ice.2015.143

22. Toda N, Hoshina T, Koga Y, Ochiai M, Kaku N, Yamamura HT, et al. Analysis of the death due to infectious diseases in the patients hospitalized in the pediatric ward of a single Japanese tertiary medical facility. Jpn J Infect Dis. (2016) 69:464-70. doi: 10.7883/yoken.JJID.2015.591

23. Bai $\mathrm{P}$, Tang $\mathrm{Y}, \mathrm{Z}$ hang W, Zeng M. Does economic policy uncertainty matter for healthcare expenditure in China: a spatial econometric analysis. Front Public Health. (2021) 9:673778. doi: 10.3389/fpubh.2021.673778

24. Su CW, Huang SW, Tao R, Haris M. Does economic overheating provide positive feedback on population health: evidence from BRICS and ASEAN countries. Front Public Health. (2021) 9:661279. doi: $10.3389 /$ fpubh.2021.661279

25. Oksuzyan A, Singh PK, Christensen K, Jasilionis D. A cross-national study of the gender gap in health among older adults in India and China: similarities and disparities. Gerontologist. (2017) 58:1156-65. doi: 10.1093/geront/gnx111

26. Str MA, Jaarsma T. Thoughts about death and perceived health status in elderly patients with heart failure. Eur J Heart Fail. (2014) 10:608-13. doi: 10.1016/j.ejheart.2008.04.011

27. Wen Y, Zong ZH, Shu XY, Zhou JF, Sun XM, Ru XM. Health status, health needs and provision of health services among the middle-aged and elderly people: results from a survey in 12 counties, 5 provinces in mid-western China. Popul Res. (2014) 5:72-86.

28. Heravi MM, Afzali H, Soleimani Z, Matin M. Common infectious diseases among the hospitalized elderly patients. Turk Geriatri Dergisi. (2011) 6:132751. doi: $10.2147 /$ CIA.S32036
29. Yang S, Wu J, Ding C, Cui YX, Zhou YQ Li YQ, et al. Epidemiological features of and changes in incidence of infectious diseases in China in the first decade after the SARS outbreak: an observational trend study. Lancet Infect Dis. (2017) 17:716-25. doi: 10.1016/S1473-3099(17)30227-X

30. Jang JH, Lee JH, Je MK, Cho MJ, Bae YM, Son HS, et al. Correlations between the incidence of national notifiable infectious diseases and public open data, including meteorological factors and medical facility resources. J Prev Med Public Health. (2015) 48:203. doi: 10.3961/jpmph.14.057

31. Maji KJ, Dikshit AK, Arora M, Deshpande A. Estimating premature mortality attributable to PM2.5 exposure and benefit of air pollution control policies in China for 2020. Sci Total Environ. (2018) 612:683-93. doi: 10.1016/j.scitotenv.2017.08.254

32. Zeng M. J Du, Zhang W. Spatial-temporal effects of PM25 on health burden: evidence from China. Int J Environ Res Public Health. (2019) 16:4695. doi: 10.3390/ijerph16234695

33. Jia Z, Li S, Wang L. Assessment of soil heavy metals for eco-environment and human health in a rapidly urbanization area of the upper Yangtze Basin. Sci Rep. (2018) 8:3256. doi: 10.1038/s41598-018-21569-6

34. Shao S, Li X, Cao JH. Urbanization and haze control in China. Econ Res J. (2019) 2:148-65.

35. Hay SI, Guerra CA, Tatem AJ, Atkinson PM, Snow RW. Urbanization, malaria transmission and disease burden in Africa. Nat Rev Microbiol. (2005) 3:81-90. doi: $10.1038 /$ nrmicro1069

36. Wu T, Perrings C, Kinzig A, Collins JP, Minteer BA, Daszak P. Economic growth, urbanization, globalization, and the risks of emerging infectious diseases in China: a review. Ambio. (2017) 46:18-29. doi: 10.1007/s13280-016-0809-2

37. Magadi MA. Understanding the urban-rural disparity in HIV and poverty nexus: the case of Kenya. J Public Health. (2017) 39:63-72. doi: 10.1093/pubmed/fdw065

38. Peng XB, Wang TY. Does social medical insurance alleviate the health inequality of minors. China Indus Econ. (2017) 12:59-77. doi: 10.19581/j.cnki.ciejournal.20171226.001

39. Vlahov D. Urban as a determinant of health. J Urban Health. (2007) 84:16-26. doi: 10.1007/s11524-007-9169-3

40. Khreis H, Nunen EV, Mueller N, Zandieh R, Nieuwenhuijisen MJ. Commentary: how to create healthy environments in cities. Epidemiology. (2017) 28:60-2. doi: 10.1097/EDE.0000000000000550

41. Neiderud CJ. How urbanization affects the epidemiology of emerging infectious diseases. Infect Ecol Epidemiol. (2015) 5:27060. doi: 10.3402/iee.v5.27060

42. Wood CL, Mcinturff A, Young HS, Kim DH, Lafferty KD. Human infectious disease burdens decrease with urbanization but not with biodiversity. Philos Trans R Soc Lond B Biol. (2017) 380:2197-223. doi: 10.1098/rstb.2016.0122

43. Bauer J, Müller R, Brüggmann D, Groneberg DA. Spatial accessibility of primary care in England: a cross-sectional study using a floating catchment area method. Health Serv Res. (2018) 53:1957-78. doi: $10.1111 / 1475-6773.12731$

44. Grossman M. On the concept of health capital and the demand for health. $J$ Polit Econ. (1972) 80:223-55. doi: 10.1086/259880

45. He LX, Nan YQ, Zhang ZG. Aging, health expenditure and economic growth: evidence from China's provincial panel data. Popul Res. (2015) 39:87-101.

46. Wang YL, Ma LJ, Pei PG. Analysis of novel coronavirus pneumonia from the theory of epidemic febrile disease. Acta Chin Med. (2019) 130:1106-7.

47. Lu M. Urban, regional and national development-the present and future of spatial political economics. China Econ Q. (2017) 4:1499-532. doi: 10.13821/j.cnki.ceq.2017.03.11

48. Wang D, Tang MG. How does land urbanization affect the quality of ecological environment? An analysis based on dynamic optimization and spatial adaptive semi parametric model. Econ Res J. (2019) 3:72-85.

49. Song LJ, Yang L. The evolution of healthy life span of the elderly and its impact-an empirical study based on CLHLS. Popul Econ. (2020) 3:57-74.

50. Qi Y, Lu HY. Pollution, health and inequality: overcoming the "environmental health poverty" trap. Manage World. (2015) 9:32-51. doi: 10.19744/j.cnki.11-1235/f.2015.09.004

51. Qin BT, Ge LM. Transfer of highly polluting industries and overall environmental pollution in China: an empirical study based on interregional 
relative environmental regulation threshold model. China Environ Sci. (2019) 8:3572-84. doi: 10.19674/j.cnki.issn1000-6923.20190604.001

52. Lu M, Li JW, Han LB. Managing urban diseases: how to achieve growth, livability and harmony. Comp Econ Social Syst. (2019) 1:22-9.

Conflict of Interest: The authors declare that the research was conducted in the absence of any commercial or financial relationships that could be construed as a potential conflict of interest.

Publisher's Note: All claims expressed in this article are solely those of the authors and do not necessarily represent those of their affiliated organizations, or those of the publisher, the editors and the reviewers. Any product that may be evaluated in this article, or claim that may be made by its manufacturer, is not guaranteed or endorsed by the publisher.

Copyright (๑) $2021 \mathrm{Yu}, \mathrm{Li}, \mathrm{Yu}$, Shi, Liu and Tian. This is an open-access article distributed under the terms of the Creative Commons Attribution License (CC BY). The use, distribution or reproduction in other forums is permitted, provided the original author(s) and the copyright owner(s) are credited and that the original publication in this journal is cited, in accordance with accepted academic practice. No use, distribution or reproduction is permitted which does not comply with these terms. 